\title{
The Social Benefits and Costs of Preserving Forest Biodiversity and Ecosystem Services ${ }^{1}$
}

\author{
Henrik Lindhjem $^{\mathrm{a} 2}$, Kristine Grimsrud ${ }^{\mathrm{b}}$, Ståle Navrud ${ }^{\mathrm{c}}$ and Stein Olav Kolle \\ DRAFT 05.04.2013 - DO NOT CITE OR QUOTE \\ ${ }^{a}$ Norwegian Institute for Nature Research (NINA), Gaustadalléen 21, N-0349, Oslo, Norway. \\ ${ }^{\mathrm{b}}$ Statistics Norway, Kongens gate 6, P.O. Box 8131 Dep, N-0033 Oslo \\ ${ }^{\mathrm{c}}$ School of Economics and Busniess, Norwegian University of Life Sciences, P.O. Box 5003, \\ N-1432 Ås, Norway.
}

Submitted to the Special issue in Journal of Environmental Economics and Policy. Around 8500 words not including tables, references and figure captions

\begin{abstract}
Ecologists recommend preserving a larger share of the old-growth forests in Norway, as half of the species have forests as their main habitat. However, progress has been slow and at the time of this study only $1.4 \%$ of the productive forest area had been preserved. We investigate benefits and costs over a 50-year period of increasing this level to 2.8\% (doubling), $4.5 \%$ ("ecologists' minimum") and 10\% (goal suggested in public debate). The benefits are estimated based on a national contingent valuation (CV) survey of Norwegian households. Two independent measures of total costs are used; i) the actual compensation amounts paid to forest owners, and ii) results from a survey of forest owners' minimum willingness-to-accept compensation to preserve. Results show that social benefits outweigh costs of all three conservation plans by a large margin. The middle option of $4.5 \%$ has the highest net present value. The results are robust to a range of assumptions, including considerations of potential hypothetical bias in benefit estimates. The results of this cost-benefit analysis reflect the preferences of the general population, the authorities and the forest owners with respect to biodiversity and ecosystem services preservation, and supplement the expert opinion of ecologists.
\end{abstract}

Keywords: forest, biodiversity, ecosystem services, contingent valuation, cost-benefit analysis.

\footnotetext{
${ }^{1}$ A preliminary version of the paper was presented at the workshop "Forest Sector Modelling and Mulitfunctionality in Forests" at INRA, Nancy, France 31. May - 1. June 2012

${ }^{2}$ Corresponding author: henrik.lindhjem@nina.no
} 


\section{Introduction}

There is currently great interest among academics (beyond mere environmental economists), bureaucrats and policymakers in the economic significance, or value, of biodiversity and ecosystem services. Starting with the Millennium Ecosystem Assessment (2005) and taken a step further in the direction of valuation through the effort of the Economics of Biodiversity and Ecosystem Services (TEEB) initiative (Kumar, 2010), much emphasis to date has been on "recognizing and demonstrating" value as a tool to open public and private eyes to the potential loss of ecosystem service benefits (e.g. Chiabai et al., 2011). This has been effective in many countries, not the least in the UK with the National Ecosystem Assessment. ${ }^{3}$ However, the next step forward is the introduction of mechanisms that can incorporate ecosystem service and biodiversity values in decision making, i.e. contribute to "capturing" such values (TEEB, 2010). Although the environmental economics literature has produced a large amount of primary valuation studies, few have been conducted for the specific purpose of contributing to or carrying out comprehensive cost-benefit analyses (CBA). Making the bridge from broad demonstrations of value to real-life CBAs of projects and policies that increase provision of, or impact, ecosystem services is essential for making non-market valuation more policy-relevant.

This paper aims to make such a bridge by conducting a comprehensive CBA of the currently much debated policy question of whether to increase forest protection in Norway. Forest conservation is an essential part of any Norwegian strategy to fulfil its obligations under the Convention on Biological Diversity, since at least half of all red list species live in forest habitats (Kålås et al., 2010). In response to conflicts erupting over command-and-control conservation in the 1980's and 90's, a national voluntary forest conservation program was initiated in Norway in the early 2000s. In this program, forest owners can submit for

\footnotetext{
${ }^{3}$ See e.g. press release and reports at: http://www.defra.gov.uk/environment/natural/uknea/
} 
consideration the whole or a part of their forest for conservation. If their forests satisfy biological criteria, especially contributions to biodiversity protection, the forest owners are compensated for reserve establishment with a one-time payment for loss of net timber values. Although the interest from forest owners so far has been good, progress has been slow due to shortage of public funds for the program. The key question is if public biodiversity and ecosystem service benefits exceed costs for various levels and ambitions of forest conservation, and if so what level of conservation maximizes net benefits. If this level is higher than the current level of conservation, the program should be allocated more resources.

We investigate this question conducting a CBA of the major cost and benefit components based on data collected for this specific purpose. First, we assess the benefits of biodiversity conservation based on a large, national contingent valuation (CV) survey of three alternative conservation plans compared to the status quo. These plans are based on actual policy alternatives that have been or are under consideration. The CV results yield willingness to pay (WTP) estimates primarily related to existence (non-use) value of increased biodiversity conservation, as reserves are often remote and inaccessible to the average recreationist. This is the primary component of the cultural ecosystem service benefits. Second, we investigate the main cost component, the opportunity costs of using the land for timber production, in two ways. First, we extrapolate total compensations that would have to be paid to private forest owners through the current conservation program based on actual compensation payments made from the start of the conservation program (Norwegian Directorate for Nature Management, 2013). Second, we conducted a CV survey of forest owners' willingness to accept (WTA) compensation to set aside their forests for reserves. WTA may be different from actual compensations, as many forest owners derive personal utility from reserve establishment. We also add to the costs, the efficiency loss of collecting taxes (marginal costs of public funds) to fund conservation and the transaction costs of implementing the plans. The 
total costs (and benefits) may to some extent depend on the policy mechanism chosen, as will be briefly discussed. The CBA follows the recent recommendations of the Norwegian public committee on CBA (NOU, 2012), for example in terms of choice of policy horizon of analysis and time-varying discount rates. We conduct a sensitivity analysis on the most important parameters for the CBA.

This is the first study we are aware of in the area of forest conservation that analyse both costs and benefits based on primary data collected for the specific purpose. Kniivilä et al. (2002) and Lehtonen et al. (2003), for example, also consider costs of conservation briefly, but have their primary focus on the benefit side. A more recent study by Naidoo and Ricketts (2006) attempt a full CBA of biodiversity conservation in Paraguay, but base many of their estimates on the literature and use rough methods for benefit transfer. Other studies, such as Bostedt and Mattson (2006) (adjusting forestry for recreation) and Slaney et al. (2010) and Chang et al. (2012) (both on pest management) consider specific forest management measures individually, rather than full conservation. Our contribution lies in the stringent incorporation of primary data on costs and benefits of conservation into a formalized CBA framework suitable for analysing the primary academic and policy issues related to forest biodiversity and ecosystem service conservation.

The paper is structured as follows. In the next section we briefly lay out the analytical framework of the CBA in terms of cost and benefit components and how they in principle are defined and measured. In section three we explain the underlying data for estimating costs and benefits. Section four presents results and the assumptions for the base case we analyse, compares costs and benefits over time in net present value (NPV) calculations, and conduct sensitivity analysis for key parameter assumptions. Even given fairly conservative assumptions regarding benefits, we find that they substantially outweigh the costs for three, 
national conservation plans investigated. We conclude and discuss the implications of these results in the final section.

\section{Analytical framework}

\subsection{Present value and policy options considered}

We investigate different levels of biodiversity conservation by establishing reserves on private forest land. This is the main vehicle for forest conservation in Norway, though there are also environmental regulations and policies governing commercial forestry activities on state and private land. We consider three alternative conservation levels measured as a percentage of the productive forest area ${ }^{4}: 2.8 \%, 4.5 \%$ and $10 \%$. At the time the CV surveys of the general public and forest owners were carried out (end of 2007), the conservation level was $1.4 \%$, so 2.8\% represented a doubling of the existing level at that time. According to an authoritative biological assessment, at least $4.5-4.6 \%$ was considered a minimum to satisfy public policy goals (Framstad et al., 2002). This is the basis for the second alternative. A more recent assessment concludes that especially low lying, very productive forests and endangered species and habitat types in southern parts of Norway are still highly underrepresented in the protected area network (Framstad et al., 2010). At least $10 \%$ protection has also been discussed as a longer term goal, and recently put forward by various interest groups as a minimum level (WWF et al., 2012). We therefore also analyse this alternative.

By January 2013 almost 2.7\% of Norwegian productive forests were conserved in reserves (Ministry of Environment (MD), 2013), but the last few years progress has been slow, as also noted by a recent OECD evaluation of Norwegian biodiversity policy (OECD, 2011). By including the $2.8 \%$ option, we can analyse retrospectively if the increase to the current level

\footnotetext{
${ }^{4}$ Productive forest is forest with a production potential of at least $1 \mathrm{~m}^{3}$ per hectare and year. Measuring conservation as a percentage of the productive forest area is a common way in many countries.
} 
was sensible from a cost-benefit perspective. The two more ambitious alternatives are still policy-relevant options.

As pointed out by for example Boadway (2006) the decision rule in an intertemporal context

is the net present value (NPV) criterion implying that the policy-maker should set a conservation level that maximizes welfare $W$ in terms of the net present value of the future (change in the) flow of net forest benefits comparing the three conservation levels with the status quo situation, as given in equation (1):

$\operatorname{Max} N P V=\operatorname{Max} W=:\left\{\sum_{t=1}^{T}\left(\frac{\Delta B_{t}^{A}-\Delta C_{t}^{A}}{\left(1+r_{t}\right)^{t}}\right)\right\}$

where $\Delta B$ is the change in the ecosystem service and biodiversity benefit flow, $\Delta C$ is the change in the cost flow, $r$ is the social discount rate (which may vary with time), $T$ the time period of the policy (which in principle for forest conservation is indefinite) and $A$ the conservation alternative considered (2.8, 4.5 and 10\%). This NPV formula can be used to rank the policy options from an economic point of view, taking account of both benefits and costs of the conservation policy to society. We will return to our assumptions for key parameters.

\subsection{Benefits}

When a reserve is established, the forest owner relinquishes his right to forestry activities for eternity. Hunting, mushroom, and berry picking and other recreational activities that do not involve setting up permanent facilities (e.g. hunters' camp) in the reserve are still allowed. Most current and proposed reserves are remote, fairly small, inaccessible and not much used by the average recreationists who rather prefer more actively managed and open forests (Gundersen and Stange, 2011). Hence, conservation of this kind can be assumed to provide mainly existence (non-use) values related to biodiversity and habitat services and cultural services. The social value of this total stream of benefits can be defined and captured by the 
beneficiaries' willingness to pay (WTP). WTP may be defined by the underlying conditional indirect utility function (e.g. Bergstrom and Taylor, 2006):

$$
V_{j}\left(P_{j}^{A}, Y_{j}-W T P^{A} ; Q_{j}^{A}, Q U A L_{j}^{A}, S U B_{j}^{A}, H_{j}, I_{j}\right)=V_{j}\left(P_{j}^{0}, Y_{j} ; Q_{j}^{0}, Q U A L_{j}^{0}, S U B_{j}^{0}, H_{j}, I_{j}\right)
$$

where, $\mathrm{P}$ is a vector of prices of market goods facing the individual (in the status quo/reference case, 0 , or for conservation alternative A), $Y_{j}$ is household income of individual $j$, Q is a measure of the quantity of forest reserves (as a percentage or number of hectares), QUAL a measure of quality of the forest reserves (e.g. a proxy for biodiversity), $S U B_{j}$ is a measure of substitutes for the forest reserve services, $H_{j}$ is non-income characteristics of individual $j$ 's household, $I_{j}$ a measure of information available to individual $j^{5}$. Solving this equation for WTP, which is identical when summed over the population, the annual change in benefits from equation (1), yields ${ }^{6}$ :

$$
\Delta B_{i}^{A} \equiv W T P^{A}=f\left(P_{j}^{A}-P_{j}^{0}, Q_{j}^{A}-Q_{j}^{0}, Q U A L_{j}^{A}-Q U A L_{j}^{0}, S U B_{j}^{A}-S U B_{j}^{0}, H_{j}, I_{j}\right)
$$

Both QUAL and Q will increase with higher conservation levels, if conservation is implemented in accordance with its intentions. ${ }^{7}$ When assuming constant prices and measures of available substitutes, which are both reasonable assumptions, (2) and (3) define WTP, the amount that can be subtracted from the individual's income so that she is indifferent between the current conservation level and the alternative and higher level A. We define the market for

\footnotetext{
${ }^{5}$ The information available to consumers is rarely perfect, and hence it is important to consider the amount and type of information available to individuals when valuing public goods, especially complex goods such as biodiversity (e.g. information given in a questionnaire as discussed subsequently).

${ }^{6}$ Note, as pointed out by Bergstrom and Taylor (2006), that in the case of demand and/or supply uncertainty, terms capturing these effects will have to be included and the resulting WTP then measures option price.

${ }^{7}$ Regarding the QUAL variable, it has been questioned in Norway to what extent voluntary conservation areas fill stated conservation gaps (Framstad and Blindheim, 2010). However, this is a matter of setting strict enough biological requirements for new enrolments in the program, and not our primary concern here. In tropical countries, a problem may be related both to the Q and QUAL variables if sufficient monitoring and enforcement are not in place to halt further degradation/deforestation after national parks/reserves are set up.
} 
the non-market good, given the geographically wide distribution and the high share of nonuse values, as the population of Norway. ${ }^{8}$

In addition to these existence values related to habitat services and biodiversity that we attempt to measure using a CV survey, there are also other, more limited ecosystem services from reserves not considered here. First, carbon sequestration services could have been calculated separately. However, the net effect in the long term of boreal forest reserves on carbon storage and atmospheric carbon compared to current forest management is uncertain and much debated (Framstad et al., 2013). The net effect depends on many factors, including the storage of carbon in soils (which is very high in northern forests), the effect of albedo ${ }^{9}$, what timber products replace in terms of energy, building materials etc. (Holtsmark, 2012). Second, the recreational (and associated health improvement) benefits related to hunting, fishing and normal everyday recreation in and around reserves will be positive, but as argued above, likely not large on a national scale due to inaccessibility and remoteness of majority of reserves. The most important recreational benefits occur in forests in and around the population centres that are typically subject to multifunctional forest management, rather than reserve protection (Lindhjem and Magnussen, 2012). The reserves will also have some marginal positive effects for flows of other regulating and supporting services, such as erosion control, water purification, flood control etc. However, such benefits are likely to be relatively limited, due to among others their relative abundance in Norway, and are therefore not included here.

\subsection{Costs}

The costs of conservation have three main components: (1) opportunity costs of taking reserves out of timber production, i.e. loss of timber provisioning services, to use the

\footnotetext{
${ }^{8}$ There may be reasons to include also non-Norwegians, as some areas may be of at least Nordic or European significance. However, to be conservative, we limit the population to the domestic population.

${ }^{9}$ How much of incoming sunlight is reflected from the surface, which depends e.g. on whether harvested forest areas are covered in snow or not.
} 
ecosystem service terminology; (2) Transaction costs related to the establishment of reserves (i.e. negotiations, biological surveys, court settlements etc.); and (3) The distortionary costs of necessary taxation to collect funds for conservation (marginal costs of public funds). Given that taxes are distortional to the economy, i.e. it is costly in efficiency terms to collect them (Sandmo, 1998), a substantial increase in conservation funding will, ceteris paribus, increase the marginal costs of public funds required to compensate forest owners and cover other costs. Hence, total social costs given in equation (1) can be broken down as:

(4) $\Delta C^{A}=\Delta \mathrm{C}_{\mathrm{OC}}^{\mathrm{A}}+\Delta \mathrm{C}_{\mathrm{T}}^{\mathrm{A}}+\Delta \mathrm{C}_{\mathrm{M}}^{\mathrm{A}}$

Where $\Delta \mathrm{C}_{\mathrm{OC}}$ is the annual change in opportunity cost for conservation alternative $\mathrm{A}, \Delta \mathrm{C}_{\mathrm{T}}$ change in transaction costs and $\Delta \mathrm{C}_{\mathrm{M}}$ the change in marginal costs of public funds. Currently, forest owners are compensated for their lost timber revenues over a standard period, subtracted harvesting costs, discounted to present values using a rate normally set at $5 \%$. The harvesting costs typically depend closely on distance to roads, topography of the terrain etc. Some forest areas, so-called zero-areas, are protected by the current timber prices, in that they are not worth harvesting.

Note that the transaction costs in many cases depend on the policy mechanism; commandand-control reserve establishment gave higher process costs than the voluntary conservation program in Norway (Skjeggedal et al., 2010). There may also be other costs from reserve establishment for example related to loss of work locally (an issue e.g. raised in Kniivilä et al. 2002). However, in Norway there is in practice full employment, and only small friction costs related to changing jobs. It is also unlikely that increased reserve protection will lead to significant loss of jobs. 


\section{Measuring costs and benefits: Methods, data and assumptions}

In this section we explain the methods used for data collection and the key assumptions made in estimating the costs and benefits of increased forest protection. We will return to the sensitivity of the results to these assumptions.

\subsection{Contingent valuation survey and benefit estimation approach}

\subsubsection{Survey design}

The survey was designed following similar forest protection surveys well tested and tried in the Nordic context (see e.g. Lindhjem (2007)), and followed recent best practice guidelines in the CV field (e.g. Bateman et al (2002), SEPA (2006)). The survey consisted of several subsamples and design elements, some of which were utilized in Lindhjem and Navrud (2009, 2011a), where more detailed descriptions of the instrument are given. Here, we only note the central features of the survey of relevance for benefit measurement. The status quo situation was described using graphs showing share of species in forests and other nature types, by using neutral pictures of red list species and by providing a map of the current reserves (see Figure 1).

Figure 1 Status quo protection level (1.4\%) in the southern part of Norway as displayed to respondents 


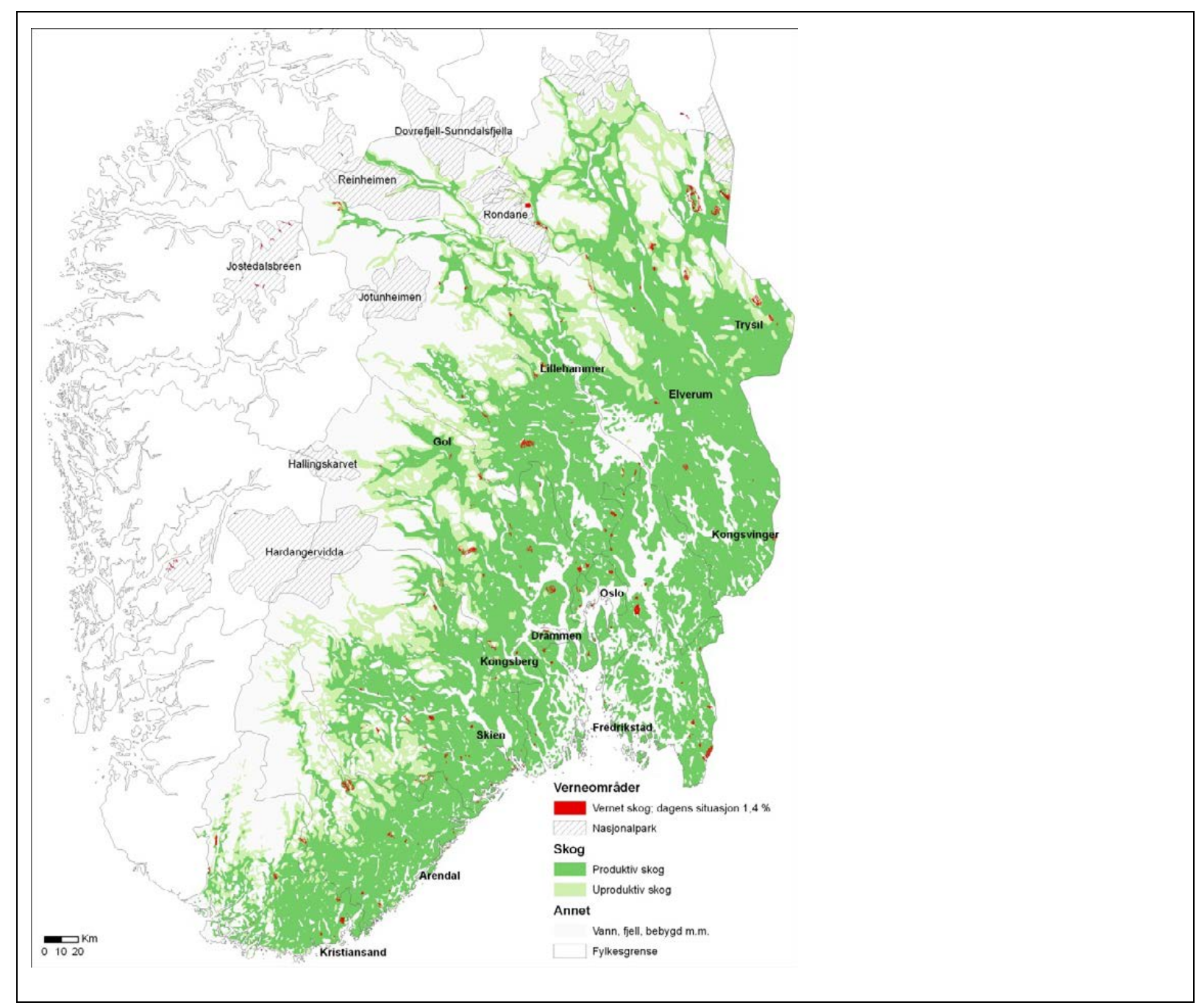

Legend: Red spots are existing reserves, dark green productive forests, light green unproductive forests.

The status quo or baseline envisaged a decline in forest biodiversity unless action was taken. Each respondent was then asked to consider two different conservation plans as an alternative to the current conservation level of $1.4 \%$ : $2.8 \%$ and either 4.5 or $10 \%$ in turn, following an advance disclosure procedure recommended by Bateman et al. (2004). The changes were described using a table noting the percentages and the hectares of conservation and the likely, general improvements that could be expected for major species groups associated with the increases in reserves (e.g. lichens, mosses, plants, fungi, insects and mammals). Since the exact location of potential new reserves had not been decided (which was noted to respondents) maps generated by GIS scaling up the polygons of existing reserves to resemble accurate depictions of the geographical extent of future reserves were provided (see an example for the largest plan of 10\% in Figure 2). 
Figure 2 Alternative, higher protection level (here 10\%) in the southern part of Norway as displayed to respondents

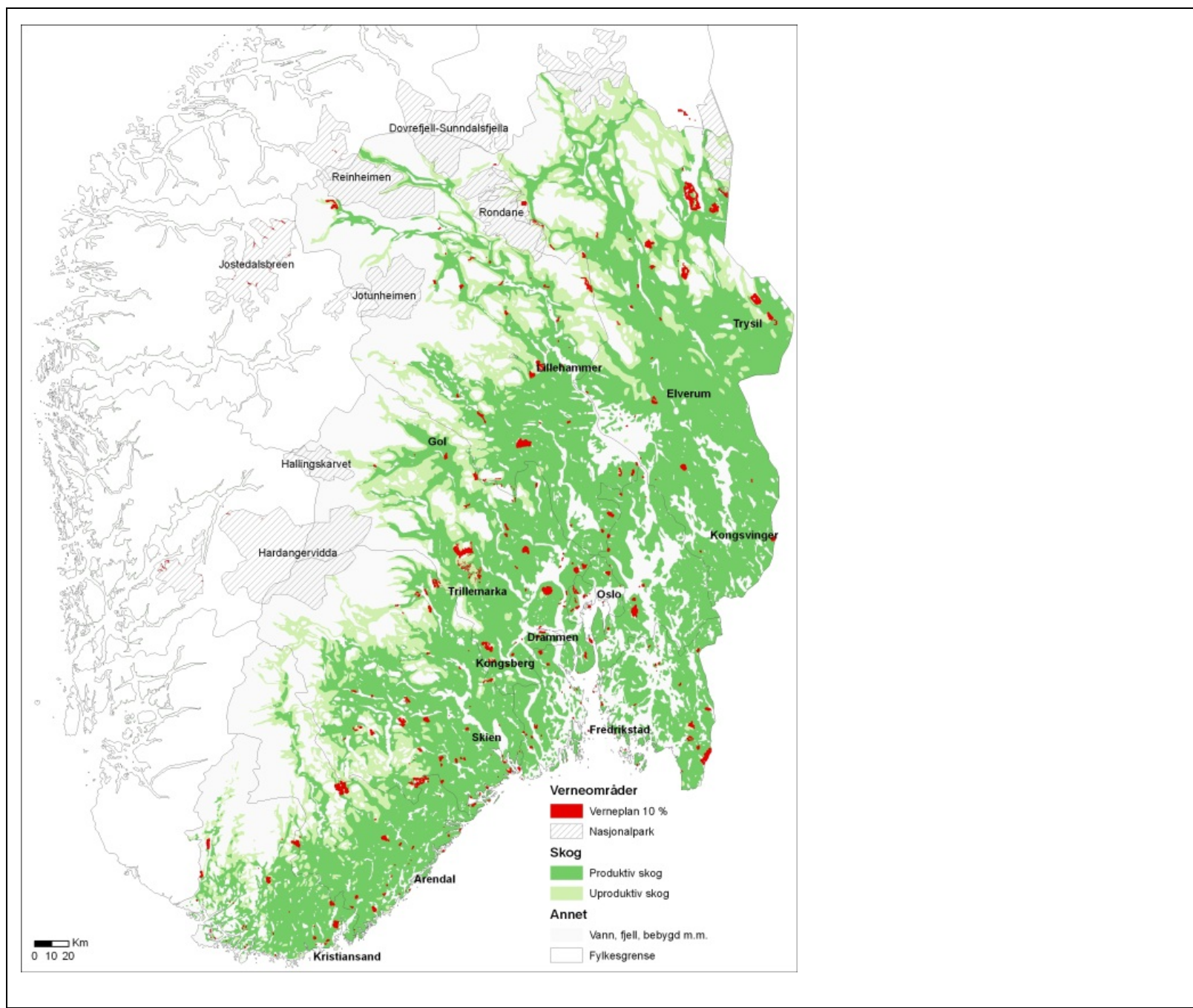

Legend: Red spots are higher level of reserve protection illustrated by scaling up existing reserves, dark green productive forests, light green unproductive forests.

The colour maps were zoomable in the web mode of the survey (see next section) and hardto-avoid technical terms in the text (such as "biodiversity", "nature reserve” etc.) were explained in boxes that would pop up when the cursor touched underlined words. ${ }^{10}$ The biological information was provided by a team of leading biologists in Norway, and checked by foresters to ensure a balanced presentation of the status quo and future plans. The respondents were for each of the two conservation plans given a WTP question asking the most, if anything, the household would be willing to pay in an additional annual tax earmarked to a public fund for increasing forest conservation from the current $1.4 \%$ to the

\footnotetext{
${ }^{10}$ In the mail survey version a list was provided at the end of the questionnaire explaining these terms.
} 
alternative levels. Note that the WTP question required an annual payment for eternity. This was chosen as these ecosystem services will be provided for eternity, and for the sake of realism as new taxes rarely are time-limited. People could then indicate their maximum WTP in a payment card in the form of a drop-down menu in the websurvey (table in postal survey) with a non-linear scale containing 23 amounts (ranging from 0 to NOK $15000^{11}$ ), including “don't know” (at the end). The amounts were chosen on the basis of previous CV studies (e.g. Lindhjem (2007)). Payment card was chosen as response format over dichotomous choice, to avoid yea saying (at the expense of theoretical incentive compatibility) (Boyle, 2003). The payment vehicle (an earmarked tax to a forest protection fund) was chosen because it is a fairly neutral, for example compared to an income tax, is realistic and reduces people's scepticism that the money would not be spent on forest protection. A typical budget reminder was included. The survey included conventional follow-up questions to determine whether zero and don't know respondents were protesting and to judge validity of the answers, including socio-economic background information of the respondents which was merged with the panel information held about the respondents (see next section).

\subsubsection{Sampling and administration}

The data were collected from an Internet survey as part of a large nation-wide multi-mode CV survey of forest protection in Norway. Although personal interviews have been recommended for CV in the past (Arrow et al., 1993), this mode also has drawbacks, especially high cost and potential social desirability bias. Internet CV surveys have been shown to give reasonable response quality and potentially lower social desirability bias leading to more conservative WTP estimates (Lindhjem and Navrud, 2011a, b). A randomly recruited panel of ca. 50,000 respondents, maintained by the professional survey firm TNS Gallup was used for the survey. Norway has one of the highest Internet broadband penetration rates (at reasonable speeds) in

\footnotetext{
${ }^{11}$ There was also an option to choose "more than 15000", in which case a box would pop up where the exact amount could be specified. 1 NOK $=0.11$ UK $£=0.13$ euro $=0.18$ US $\$$ (nominal exchange rates April 2013).
} 
the world at around 95\%. The survey was conducted on a representative sample of the Norwegian adult (>15 years of age) population in October-November 2007. To be sure to cover the older part of the population who normally are less computer literate, two additional small samples were recruited from the same panel to cover this group of respondents and a survey version adapted for a normal mail survey. The net sample was 2881completed responses in four main samples. Table 1 gives an overview of the samples used for calculating mean WTP.

Table 1 Samples, sample sizes and splits on survey mode and valuation scenarios

\begin{tabular}{|l|c|c|c|c|}
\hline & \multicolumn{2}{|c|}{ Web survey } & \multicolumn{2}{c|}{ Postal survey } \\
\hline & Sample I & Sample II & Sample III & Sample IV \\
\hline \# observations (gross) & 900 & 2250 & 250 & 250 \\
\hline Protection levels 2,8\% \& 4,5\% & $\sqrt{ }$ & & $\sqrt{ }$ & \\
\hline Protection levels 2,8\% \& 10\% & & $\sqrt{ }$ & & $\sqrt{ }$ \\
\hline
\end{tabular}

Notes: The number of observations for the 2.8 and $10 \%$ are higher than for 2.8 and $4.5 \%$ because there were some additional split samples for the former protection levels that for simplicity are pooled here.

Before fielding the survey, the instrument went through thorough testing in focus groups and two pilots, requiring only small changes before implementation.

\subsubsection{Econometric estimation of mean WTP}

Answers to the WTP questions using a payment card return interval data. For simplicity we take respondents' true WTP as interval mid-points (except for zeros, see below) and estimate the simple mean of the distribution following procedures described in e.g. Cameron and Huppert (1989). ${ }^{12}$ Given the many payment card amounts, the distribution should follow the true WTP distribution fairly closely (others using this approach is e.g. Bateman et al., 2005). ${ }^{13}$

\footnotetext{
${ }^{12}$ Note that we for simplicity treat the two WTP responses from each respondent as independent (i.e. no panel data considerations).

${ }^{13}$ An alternative to this is to use an interval estimation approach (see e.g. Mahieu et al., 2012) where WTP $>0$ is assumed to have a log normal distribution. We also tested this alternative and found similar (but slightly higher) values compared to those reported in Table 2 below.
} 
Respondents that stated zero or don't know were interpreted, following coventional CV procedures, either as a statement of true zero (conservative) and included, or as protesters and therefore removed (base case, assuming in effect that protesters have WTP equal to the average), if they stated at least one protest reason out of two possible reasons from a battery of alternatives. ${ }^{14}$ We also use a procedure sometimes applied in the CV literature to remove some of the outliers, identified as WTP amounts higher than $2 \%$ of stated household income (see e.g. Veisten et al., 2004). This is a conservative choice.

The survey did not specify explicitly when respondents could expect the plan to be implemented, but it was clear that it would happen in the very short term. For the analysis, we assume the benefits starting from the first year.

\subsection{Opportunity cost measurement - actual and hypothetical compensation}

\subsubsection{Actual compensation payments}

Actual compensations are paid as a one-time amount to reflect the true opportunity costs of forest owners related to commercial forestry activities. From the Norwegian Directorate of Nature Management we have obtained the complete data on actual payments made during the voluntary forest conservation program from the start in 2003 until January 2013. In 2012, no new areas were established due to lack of funds. The data contain 138 new reserves, out of which we have disclosed compensation payments for 132. The data contain variables for total size of the forest, the productive part of the forest, a five scale biological quality indicator, the location of the reserve down to the municipality level ${ }^{15}$ and the payment made. We use these data to derive a simple cost estimate for expanding the current forest reserves, assuming for simplicity that the chosen conservation level can be reached in year one. ${ }^{16}$

\footnotetext{
${ }^{14}$ All other reasons than clear statements of no benefit from or no budget for conservation were interpreted as protest.

15 The actual coordinates of the reserves are currently not public information.

${ }^{16}$ A more realistic scenario would be for example to assume a plan that implements e.g. $10 \%$ of the conservation increase each year. However, this complicates calculations, both for costs and benefits, and is not in line with what respondents were presented in the survey. We therefore stick with this simplifying assumption.
} 


\subsubsection{Forest owner WTA survey data}

In addition to the actual compensation data, we also conducted a CV survey of forest owners to assess their WTA to enrol their forests into the voluntary forest programme. The motivation for this was that forest owners may derive some utility themselves from conserving their forests and therefore not necessarily require full compensation (Raunikar and Buongiorno, 2006). However, there are several challenges in revealing true WTA through a survey like this, for example the risk of strategic responding. ${ }^{17}$ The CV data were analysed in Lindhjem and Mitani (2012), and more details of the survey are provided there. The main part of the questionnaire concerned whether the forest owner would consider enrolling the whole or parts of his forest given sufficient compensation. If so, there were questions about approximate share of the total forest property to enrol, and questions zooming in on the characteristics of that parcel in terms of harvesting costs, richness in timber and presence of 10 key biological elements (such as dead trees, known red list species, significant presence of deciduous trees etc). Following this, was an open-ended WTA question, aided by a payment card $^{18}$, asking about the minimum compensation per $5 \operatorname{dekar}^{19}$ as an annual payment to set aside the forest for reserve. Annual payment was chosen to make it easier for forest owners to arrive at a WTA estimate, but it may have drawbacks, since this is different from the one-time payment that some forest owners probably were familiar with. ${ }^{20}$ Similar to a general CV survey, the survey ended with follow-up questions about WTA/enrolment and socio-economic background information.

\footnotetext{
${ }^{17}$ It was made clear that the answer would not be used to estimate compensation for this forest in particular, to remove any worries about our intentions and potentially reduce strategic answering.

${ }^{18}$ Amounts ranging from NOK 0 to 2000 were chosen in consultation with forestry experts to cover the typical value range of rents from timber in a Norwegian forest.

${ }^{19}$ A common area unit for forestry in Norway, corresponding to 0.5 hectares (ha).

${ }^{20}$ Note that compared to the CV survey of the environmental benefits above, where the good people value is the same across respondents (except of course for subsamples getting different-sized conservation plans), the WTA stated in the forest owner survey may depend both on the different characteristics of the forest property as well as the preferences of the forest owner. That is the reason for collecting the extra information about the specific plot forest owners would like to enrol.
} 
Early versions of the survey instrument were tested in two video-taped focus groups conducted in two separate locations and the survey also underwent pilot testing among forest owners and managers. The sample frame was an official list with the names and contact information of Norwegian forest owners obtained from government forest tax records. All forest properties located in the ten counties in southern, middle and eastern Norway (covering the large majority of forests of potential interest for conservation) larger than 25 hectares were selected to an adjusted list. ${ }^{21} 2007$ forest owners were then randomly drawn from the adjusted list. The questionnaire and a cover letter explaining the objective and importance of the study were mailed to the forest owners in November 2007 by TNS Gallup following an approach modified from Dillman (2000). Data collection ended in January 2008.

Since the stated WTA was given for the total forest area the respondent would enrol, we used the sample estimate of productive forest share to adjust the WTA. We use this mean, annual WTA estimate for sensitivity and the real compensation data for the base case.

\subsection{Transaction costs and marginal costs of public funds}

The transaction costs associated with reserve establishment, $\Delta \mathrm{C}_{\mathrm{T}}$, are likely to vary with the size and number of reserves, and with the policy mechanism chosen. We do not have detailed data about the transaction costs, and this is in principle also hard to measure (Brouwer et al., 2011). For simplicity, we estimate $\Delta \mathrm{C}_{\mathrm{T}}$ as a fraction of the opportunity costs, i.e. the compensation payment, $\Delta \mathrm{C}_{\mathrm{OC}}$. Skjeggedal et al. (2010) estimate, based on a large forest owner survey used to evaluate the functioning of the voluntary program, transaction costs of around $20 \%$ for the voluntary program and $35 \%$ for the command-and-control program that was used previously.

\footnotetext{
${ }^{21}$ The cut-off point of 25 ha was chosen because, from an ecological perspective, smaller properties would not contribute significantly to conservation purposes.
} 
Estimating the marginal costs of raising public funds, $\Delta \mathrm{C}_{\mathrm{M}}$, we follow the guideline by Norwegian Ministry of Finance (2005), which recommends assuming that 1 NOK for a public project or policy in tax costs 0.2 NOK to raise. This means in practice that we add $20 \%$ to the opportunity costs and transaction costs of conservation.

\section{Analysis and results}

\subsection{Estimation of benefits}

The weighted response rate for the samples in Table 1 of the CV survey was $69 \%$, which is very high also by Internet panel standards. The samples showed fairly good representativeness compared to the Norwegian population along dimensions of gender, age distribution and education. $^{22}$ Table 2 and Figure 3 display the estimated mean WTP for the three conservation plans.

Table 2 Midpoint estimates of annual, mean WTP per household for the three forest conservation plans, measured in October 2007 NOK.

\begin{tabular}{|l|l|l|l|l|l|l|l|l|}
\hline & \multicolumn{6}{|l|}{ Mean WTP, only outliers excluded* } & \multicolumn{2}{l}{$\begin{array}{l}\text { Mean WTP, protesters and outliers } \\
\text { excluded, base case** }\end{array}$} \\
\hline $\begin{array}{l}\text { Conservation } \\
\text { plan }\end{array}$ & $\begin{array}{l}\text { Mean } \\
\text { WTP }\end{array}$ & $\begin{array}{l}\text { 95\% CI } \\
\text { (LB, UB) }\end{array}$ & $\begin{array}{l}\text { Sample } \\
\text { size }\end{array}$ & $\begin{array}{l}\text { Mean } \\
\text { WTP }\end{array}$ & $\begin{array}{l}\text { 95\% CI } \\
\text { (LB, UB) }\end{array}$ & $\begin{array}{l}\text { Sample } \\
\text { size }\end{array}$ \\
\hline $1.4 \%$ to $2.8 \%$ & 693.1 & 643.3 & 742.9 & 2855 & 1038.7 & 968.5 & 1108.9 & 1837 \\
\hline $1.4 \%$ to $4.5 \%$ & 796.3 & 678.8 & 913.7 & 793 & 1248.4 & 1068.4 & 1428.4 & 480 \\
\hline $1.4 \%$ to $10 \%$ & 871.6 & 801.8 & 941.3 & 2035 & 1300.3 & 1202.8 & 1397.9 & 1334 \\
\hline
\end{tabular}

Notes:

* Don't know and zero responses are interpreted as WTP $=0$, no protest responses dropped.

**Don't know and zero responses interpreted as protest and removed if at least one (out of a possible two) stated reasons indicated protest.

For both estimations outliers (WTP $>2 \%$ ) of household income were excluded. For * the number of outliers removed were 26,8 and 32 for conservations plans, $1.4-2.8 \%, 1.4-4.5 \%$, and $1.4-10 \%$, respectively. For ** an additional 1018, 313, and 701 observations were removed for conservations plans, $1.4-2.8 \%, 1.4-4.5 \%$, and 1.4$10 \%$, respectively

\footnotetext{
${ }^{22}$ There was some slight overrepresentation of higher educated, males in the age group 30-44, which is often observed in such surveys. Since public information about the income distribution is not easily available, we instead compared the income data for respondents and non-respondents in the webpanel. A t-test revealed no significant difference in income levels between respondents and non-respondents. We decided not to weigh the data.
} 


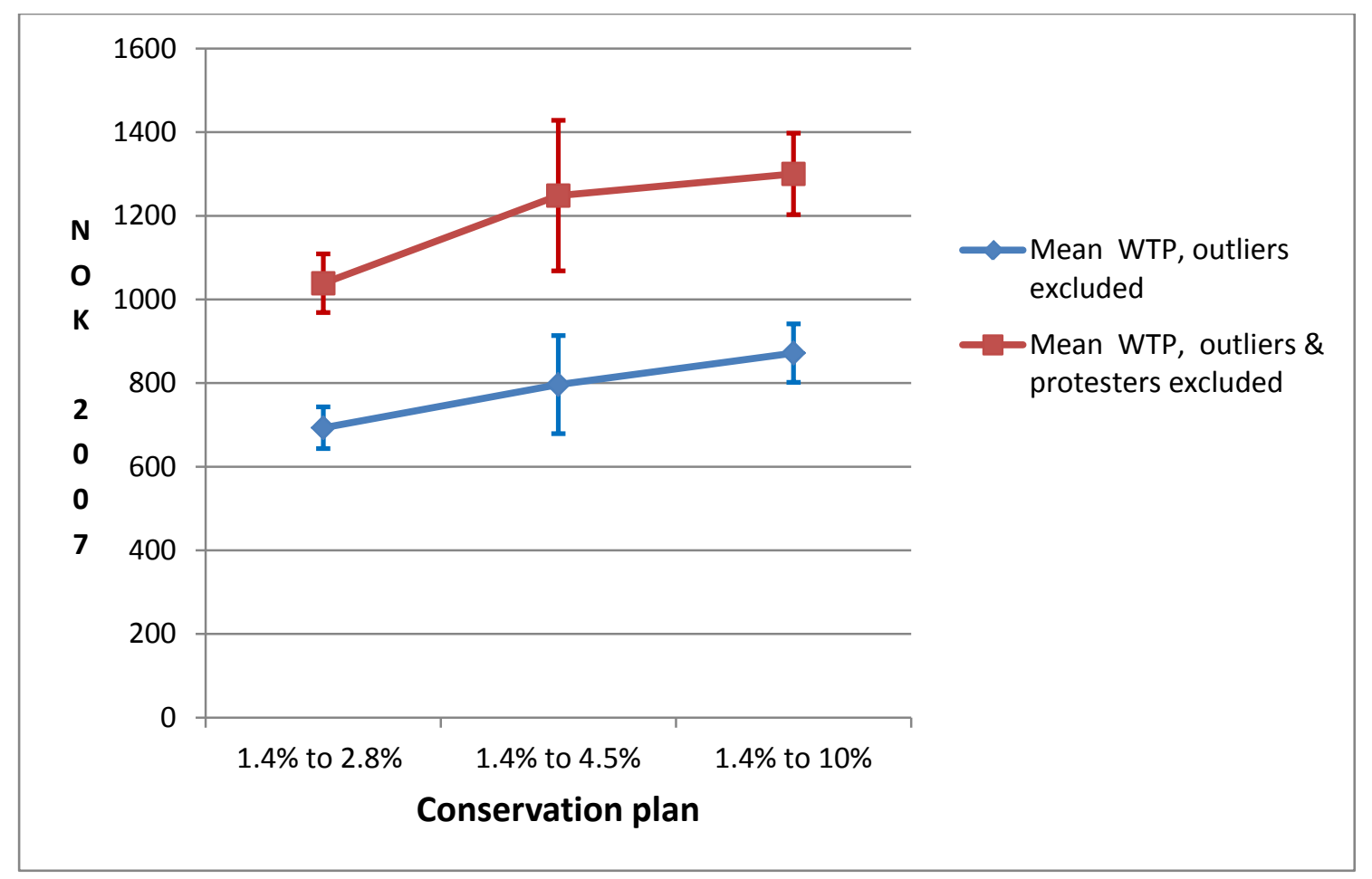

Figure 3 Midpoint estimates of annual, mean WTP per household for the three forest conservation plans, measured in October 2007 NOK. 95\% CI in vertical bars.

For the samples and WTP questions taken together around 386 indicate “don’t know” and 824 zero. The mean WTP is therefore quite sensitive to the treatment of zero/don't know respondents. ${ }^{23}$ The most conservative approach of treating all don’t knows and zeros as true zero responses (main column 2 in Table 2, lower graph in Figure 3) yield annual, mean WTP estimates from NOK 693 to 872 depending on the scope of the plan. Looking instead at the reasons people state for their responses, give a more nuanced (and likely truer) picture and a higher mean WTP from NOK 1039 to 1300 depending on the plan (main column 3 in Table 2, higher graph in Figure 3). Note that due to a lower sample size, the confidence interval is wider on WTP for the $4.5 \%$ plan.

A full validity check of the data, which is recommended for fully-fledged CV studies, is beyond the scope of this paper, but we offer a few observations. First, note that mean WTP is not significantly higher for the $4.5 \%$ and $10 \%$ plans compared to $2.8 \%$, since the confidence

\footnotetext{
${ }^{23}$ An alternative procedure for excluding protesters of requiring both statements to be related to protest yield the following intermediate mean WTP estimates: NOK $857(797.4,916.6)$ for $2.8 \%$, NOK $1009.9(862.4,1157.3)$ for $4.5 \%$ and NOK $1080.6(996.4,1164.8)$.
} 
intervals overlap. However, a more correct test of internal scope would be a paired t-test since each respondent received two WTP questions where the second question concerned a higher protection plan. Using paired t-tests on the midpoint estimates, we find that the WTP for the larger conservation plans are significantly $(\mathrm{p}<0.02)$ greater than for the smaller plan. ${ }^{24}$ Thus, visual inspection of the table gives the incorrect impression of internal scope insensitivity. However, we did not find a significant difference between mean WTP for $4.5 \%$ and $10 \%$ in split samples (i.e. comparing mean WTP for those who received $4.5 \%$ and $10 \%$ as their second WTP question). ${ }^{25}$ Putting too much weight on the lack of external scope as a sign of unreliable data would be too simplistic, as there may be good reasons for not having higher WTP for the $10 \%$ plan compared to the $4.5 \%$ plan (Amiran and Hagen, 2010; Lindhjem, 2007). Marginal existence value may be diminishing (Rollins and Lyke 1998) or respondents may even feel that as long as a sufficient amount of biodiversity is preserved for the species not to be threatened anymore, it is good enough (Jacobsen et al., 2012). The detailed reasons behind scope (in)sensitivity in these data is a topic of on-going research. For our purpose her, we use the mean WTP estimates for the respective plans in the cost-benefit comparison. ${ }^{26}$ Aggregate WTP for all Norwegian households can be estimated by multiplying the estimates of mean WTP from Table 2 by the number of Norwegian households in 2007, which was 1998 822. We use these totals as basis and adjust with the increase in the consumer price index (CPI) to 2013 and household numbers in the CBA comparison below to get the aggregate WTP in 2013 NOK.

\footnotetext{
${ }^{24}$ More correct would be to conduct this test by comparing mean WTP when only WTP $>0$ respondents are included. We conducted such a test, excluding outliers, and found that WTP for the $4.5 \%$ plan was greater than for the $2.8 \%$ plan (onesided test, $\mathrm{p}<0.05$ ) and that the WTP for the $10 \%$ plan was greater than for the $2.8 \%$ plan (one-sided test and two-sided test, $\mathrm{p}<0.01$ ).

${ }^{25}$ Two-sample t-test with unequal variances, showed no significant difference between means. This held both with and without zero responses included.

${ }^{26}$ As a validity check we ran some simple regressions (results left out for brevity) for our specific samples explaining variation of WTP. These show that WTP vary with variables expected from theory and previous empirical research, such as income and frequency of recreational use. Lindhjem and Navrud (2009, 2011a) also carry out validity checks of some of the subsamples from the same dataset and find responses reliable (and no less so than the part of the data collected through personal interviews as analysed in Lindhjem and Navrud 2011a).
} 


\subsection{Estimation of costs}

\subsubsection{Costs based on actual compensation payments}

The mean compensation payment per hectare productive forest was estimated at NOK 27537 with 95\% confidence interval of (24 637, 30 437). Note that there is not much variation in the compensation payments. We use the mean estimate to scale up the compensation costs. The total costs, including transaction and taxation costs are displayed in Table 3.

Table 3 Total costs for the three conservation plans, measured in NOK Jan. 2013.

\begin{tabular}{|c|c|c|c|c|c|}
\hline $\begin{array}{l}\text { Conservation } \\
\text { plan }\end{array}$ & $\begin{array}{l}\text { Extra } \\
\text { ha* }\end{array}$ & $\begin{array}{l}\text { Compensation } \\
\text { costs }\end{array}$ & $\begin{array}{l}\text { Transaction costs } \\
\text { voluntary } \\
\text { program }(\mathrm{CAC})^{\S}\end{array}$ & $\begin{array}{l}\text { Taxation costs } \\
\text { (incl. CAC cost) }^{\S}\end{array}$ & $\begin{array}{l}\text { Total costs } \\
\text { (incl. CAC costs) }^{\S}\end{array}$ \\
\hline $1.4 \%$ to $2.8 \%$ & 105000 & 2891385000 & 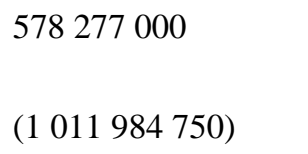 & $\begin{array}{l}693932400 \\
(780673950)\end{array}$ & $\begin{array}{l}4163594400 \\
(4684043700)\end{array}$ \\
\hline $1.4 \%$ to $4.5 \%$ & 225000 & 6195825000 & $\begin{array}{l}1239165000 \\
(2168538750)\end{array}$ & $\begin{array}{l}1486998000 \\
(1672872750)\end{array}$ & $\begin{array}{l}8921988000 \\
(10037236500)\end{array}$ \\
\hline $1.4 \%$ to $10 \%$ & 635000 & 17485995000 & 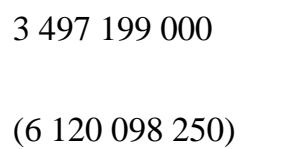 & $\begin{array}{l}4196638800 \\
(4721218650)\end{array}$ & $\begin{array}{l}25179832800 \\
(28327311900)\end{array}$ \\
\hline
\end{tabular}

Notes:

* As of 2007 and the info provided in the CV survey of WTP.

$\S \mathrm{CAC}=$ command and control conservation, i.e. administrative expropriation of land. Numbers in brackets are showing these costs instead of the assumed costs of the voluntary program.

The total costs are ca. 4.2, 8.9 and 25.2 billion NOK in total for the three conservation plans.

Using the mean compensation estimate per hectare as a measure of opportunity costs of expanding the conservation network makes sense if we assume that the additional enrolled productive forests will resemble the land currently enrolled, i.e. in terms of size of reserves etc. We have no good reasons to do otherwise, i.e. to make assumptions regarding the curvature of the cost function. A simple regression analysis of the compensation data indicate a near log-linear relationship between the compensation amount paid and the productive 
forest size enrolled, i.e. the compensation increases percentage wise at almost the same rate as the size. ${ }^{27}$ We did not find a time trend in compensations, above general increase in the CPI.

Transaction costs are highly uncertain and there may be reasons to assume that they will decline as program administrators learn. We use, however, the current estimate as our best guess.

\subsubsection{Costs based on WTA data}

The CV survey of forest owner resulted in 756 usable responses and an overall adjusted response rate of $38.5 \%$, which is quite good for this kind of survey. ${ }^{28}$ The mean WTA compensation from the CV survey of forest owners was estimated by Lindhjem and Mitani (2012) at around 1800 (NOK 2007) per hectare of total forest enrolled per year, or more accurately NOK $1790.50 .{ }^{29}$ Utilizing the sample average productive forest share of $73.6 \%{ }^{30}$, we adjust this estimate to be applicable per hectare of productive forest to NOK 2433.

In Table 4 we have summarized the annual compensation costs for the three plans, based on this estimate. This annual "rental payment" will exceed the one-time compensation payment above, depending on assumptions for the time horizon of payments and the discount rates.

Table 4 Annual costs for the three conservation plans based on WTA CV survey data, measured in NOK 2007.

\begin{tabular}{|l|l|l|l|l|l|}
\hline Conservation & Extra ha* & Compensation & Transaction & Taxation costs & Total costs \\
\hline $1.4 \%$ to $2.8 \%$ & 105000 & 255465000 & 51093000 & 61311600 & 367869600 \\
\hline $1.4 \%$ to $4.5 \%$ & 225000 & 547425000 & 109485000 & 131382000 & 788292000 \\
\hline
\end{tabular}

\footnotetext{
${ }^{27}$ Coefficient of 0.775 on log productive forest area, t-value of 19.43 .

${ }^{28}$ There were some signs of non-response bias, as analysed by Nybakk et al. (2009), in that respondents had significantly ( $\mathrm{p}<$ $0.05)$ higher education and were significantly $(\mathrm{p}<0.05)$ younger than nonrespondents. None of these variables were significant in the analysis of Lindhjem and Mitani (2012), so we decided for simplicity not to weigh the data.

${ }^{29}$ Taking the mean of the two estimates in Table 3 of Lindhjem and Mitani (2012). The corresponding standard error of this estimate is 220.3 .

${ }^{30}$ Table 2 of Lindhjem and Mitani (2012).
} 


\begin{tabular}{|l|l|l|l|l|l|}
\hline $1.4 \%$ to $10 \%$ & 635000 & 1544955000 & 308991000 & 370789200 & 222435200 \\
\hline
\end{tabular}

* As of 2007 and the info provided in the CV survey of WTP.

The total, annual costs in this case vary from 367 million to 2.2 billion NOK. Lindhjem and Mitani (2012) model WTA as a function of a number of variables, and show some degree of validity in responses, e.g. that WTA depends on the size of the proposed reserve, the productive forest share and whether the owner resides locally. This is information that may be used for targeting the program to reduce costs, which we will discuss subsequently. For the base case, we use the mean WTP estimate for all additional hectares conserved assuming that increased protection will resemble the sample, mean forest owner and property characteristics.

\subsection{Cost-benefit comparisons for the base case}

In this section we compare the benefit and cost estimates for our base case. In addition to the assumptions substantiated above for the individual, mean estimates, we need to add a few more here. First, the time horizon we choose is 50 years, i.e. from 2013 to 2063. Although the benefit flow from conservation in principle is eternal, a limit for the practical CBA has to be set, not least since uncertainty related to key parameters becomes large in the longer term. NOU (2012) recommends for example 40 years for major infrastructure projects and does not rule out much longer time horizons. The Norwegian Government has recently presented a White Paper making predictions for Norway until the 2060s (Ministry of Finance, 2013), and we therefore conveniently adopt assumptions made there related to growth in GDP and number of households for the next 50 years. We use the risk adjusted discount rates recommended in NOU (2012) of $4 \%$ for the first 40 years and 3\% years thereafter. ${ }^{31}$ A key question is how people's preferences for forest conservation develop over time, e.g. due to increasing scarcity of biodiversity and increasing incomes. Due to limited knowledge about

\footnotetext{
${ }^{31}$ The international debate on the choice of discount rate is extensive and a «second wave» of research was initiated in the wake of the Stern Review from 2006, which recommended lower discount rates for climate mitigation than economists traditionally had used in CBA. Recommendations on discount rates currently vary between countries. The UK Green Book from 2003 (HM Treasury, 2003), for example, differ from the Norwegian NOU (2012). NOU (2012) recommends $3 \%$ until year 75 and then $2 \%$ beyond, while HM Treasury (2003) recommend several time horizons and lower rates.
} 
this, NOU (2012) recommends not to adjust WTP according to income growth, though they refer to some literature showing a span of elasticities from 0.3 to 0.6 . We follow the conservative recommendation of not adjusting here. We adjust the WTP estimates with the CPI starting from 2007. Cost estimates based on actual compensations will be incurred today and are in any case not subject to price or value adjustments. Table 5 below summarises the net present values for the three conservation plans.

Table 5 Present value of cost and benefit components for the three conservation plans for the base case, changes in NOK million 2013.

\begin{tabular}{|l|l|l|l|}
\hline Conservation plan: & $\mathbf{2 . 8 \%}$ & $\mathbf{4 . 5 \%}$ & $\mathbf{1 0 \%}$ \\
\hline Present value of benefits: & 152291.0 & 183036.6 & 190646.0 \\
\hline Total quantified conservation benefits & \multicolumn{2}{l|}{} \\
\hline Present value of costs: & 2891.4 & 6195.8 & 17486.0 \\
\hline Compensation costs (opportunity costs) & 578.3 & 1239.2 & 3497.2 \\
\hline Transaction costs & 693.9 & 1487.0 & 4196.6 \\
\hline Inefficiency costs of taxation & 4163.6 & 8922.0 & 25179.8 \\
\hline Total quantified costs & & & \\
\hline & $\mathbf{1 4 8} \mathbf{1 2 7 . 4}$ & $\mathbf{1 7 4} \mathbf{1 1 4 . 6}$ & $\mathbf{1 6 5} \mathbf{4 6 6 . 2}$ \\
\hline Net present value (NPV) of net benefits
\end{tabular}

The NPV of the forest conservation benefits are estimated at 152 billion for 2.8\%, 183 billion for $4.5 \%$ and 190 billion for 10\%. The costs vary from 4 to 25 billion. The NPV of net benefits of conservation are therefore from 148 to 174 billion, with the middle option of $4.5 \%$ as the best, which is the minimum conservation level recommended by biologists. This means that retrospectively, the increase from $1.4 \%$ to around $2.7 \%$ today also was an efficient choice. There is a large gap between benefits and costs. The robustness of this conclusion we discuss in the next section. 


\subsection{Sensitivity analysis}

We first include the more conservatively estimated mean WTP from Table 2, where outliers are excluded but all zero and don’t know responses are interpreted as “true” zero. This gives the results in Table 6.

Table 6 Present value of cost and benefit components for the three conservation plans for the case where don't know and zero responses = true zero, NOK million 2013.

\begin{tabular}{|l|l|l|l|}
\hline Conservation plan: & $\mathbf{2 . 8 \%}$ & $\mathbf{4 . 5 \%}$ & $\mathbf{1 0 \%}$ \\
\hline Present value of benefits: & \multicolumn{3}{|l|}{} \\
\hline Total quantified forest conservation benefits & 101605.5 & 116751.1 & 127791.3 \\
\hline Present value of costs: & \multicolumn{3}{|l|}{} \\
\hline Compensation costs (opportunity costs) & 2891.4 & 6195.8 & 17486.0 \\
\hline Transaction costs & 578.3 & 1239.2 & 3497.2 \\
\hline Inefficiency costs of taxation & 693.9 & 1487.0 & 4196.6 \\
\hline Total quantified costs & 4163.6 & 8922.0 & 25179.8 \\
\hline & & & \\
\hline Net present value (NPV) of net benefits & $\mathbf{9 7 4 4 2 . 0}$ & $\mathbf{1 0 7} \mathbf{8 2 9 . 1}$ & $\mathbf{1 0 2} \mathbf{6 1 1 . 5}$ \\
\hline
\end{tabular}

This reduced the present value of benefits by around 30\%, but the overall conclusion is the same as above. Table 7 displays the case where costs instead are calculated using the estimated WTA. Since we are considering a time period of 50 years, the WTA-based costs that are annual becomes higher in present value terms than the one-off compensations in Tables 5 and 6. Again, all three conservation plans are socially beneficial, with the middle plan as the preferred. Note that the WTA estimates are more uncertain than the costs estimates based on actual compensation payments. 
Table $7 \quad$ Cost and benefit components, annual changes in NOK million 2013. Cost method 2: WTA Compensation.

\begin{tabular}{|l|c|c|c|}
\hline Conservation plan: & $\mathbf{2 . 8 \%}$ & $\mathbf{4 . 5 \%}$ & $\mathbf{1 0 \%}$ \\
\hline Present value of benefits: & 152291.0 & 183036.6 & 190646.0 \\
\hline Total quantified forest conservation benefits & 12988.7 & 27832.9 & 78550.5 \\
\hline Present value of costs: & 2597.7 & 5566.6 & 15710.1 \\
\hline WTA & 3117.3 & 6679.9 & 18852.1 \\
\hline Transaction costs & 18703.7 & 40079.3 & 113112.8 \\
\hline Inefficiency costs of taxation & & & \\
\hline Total quantified costs & $\mathbf{1 3 3} \mathbf{4 8 4 . 7}$ & $\mathbf{1 4 2} \mathbf{9 5 7 . 3}$ & $\mathbf{7 7 5 3 3 . 3}$ \\
\hline
\end{tabular}

Finally, we added the higher transaction costs for the command and control type conservation, which increase costs somewhat, but not enough to outweigh benefits by a large margin.

In a real-world CBA such as the one conducted here, it is necessary to make a number of assumptions. Many of the ones we have made are relatively conservative in terms of not overestimating benefits. In principle, for example, there are good reasons to expand the horizon to eternity, use a lower discount rate or to adjust benefits by increase in GDP over time. ${ }^{32}$ These would all increase benefits substantially. It could also be argued that opening for much longer horizons, higher losses for the forests owners need to be calculated, included option values (e.g. using the land for recreational home development) currently not compensated. However, note also that the transactions costs we have assumed are linear, e.g. not incorporating any likely efficiency or learning gains achieved once the relatively new voluntary program have been in operation for more years. The cost estimates we have used are more likely on the high than on the low side (see conclusions).

So, are benefits “real” and as real as the costs, which come directly out of taxpayers' pockets? The most serious critique of the CV method has been hypothetical bias, i.e. that respondents state higher WTP than they would actually pay if faced with a real trade-off in the

\footnotetext{
${ }^{32}$ Note that for certain combinations of discount rates and elasticities with respect to income, the benefit side may not converge.
} 
marketplace. This is generally a valid criticism, though we are far from understanding fully why such bias exists (Loomis 2011). Loomis (2011) discusses several approaches to deal with the bias ex ante in survey design and ex post in data calibration. There is evidence that selfimage associated with morally commendable behaviour, for example "donating” to biodiversity conservation, gives higher hypothetical bias than paying for more morally neutral goods (Johansson-Stenman and Svedsäter 2012). Two much-cited meta-analyses investigating the bias find factors of stated to actual WTP from 1.35 to 3 (Murphy et al 2005; List and Gallet 2001). Note that in our base case for costs to be equal to benefits the hypothetical bias factor would have had to be 36.6, 20.5 and 7.6 for the three plans, respectively. There is no evidence in the literature for such high factors. For the even more conservative WTP estimates in Table 6 above, the same factors would have had to be 24.4, 13.1 and 5.1, which are still unrealistically high. This means that our main conclusion is robust also to hypothetical bias calibration ex post.

\section{Concluding remarks}

We have conducted a real-world CBA of the social costs and benefits of forest conservation in Norway, with particular emphasis on the cultural ecosystem services derived over a 50 year time horizon. The results show clearly that benefits are substantially higher than the costs, and that the middle option of increasing protection from $1.4 \%$ of the productive forest area to $4.5 \%$ is the most beneficial plan. This result is highly robust, also if a factor of potential substantial hypothetical bias in the WTP estimates is included in the considerations.

Although there are many studies in the stated preference literature attempting to value biodiversity conservation and cultural services, very few take the next step to conduct a full CBA. Our investigations showed that making this step requires a number of assumptions, e.g. about people’s preferences for such services over time, for which there is little knowledge in the literature. More research clearly needs to go into this area for CBA results to stand on 
firmer ground. And given the lack of knowledge, the risk is in our opinion an underestimation of the value of environmental goods over time, rather than overestimation. NOU (2012), for example, was not comfortable recommending adjustments of the value of environmental goods over time based on estimates of the elasticity of WTP with respect to income. ${ }^{33}$

We have in our analysis not investigated spatial differentiation explicitly, partly due to lack of such information but also because we prioritised to investigate the issue on a general and principal level. With more knowledge of the spatial variation in opportunity costs and biologically valuable areas, it would have been possible to target conservation to those areas that give the highest biodiversity gains for the lowest opportunity costs. This would have given the basis for more specific cost and benefit estimates for the three conservation plans and most likely lower overall costs as a result. See e.g. Naidoo and Ricketts (2006) or the UK NEA for illustrative spatially explicit applications.

As we have seen, the way conservation is implemented may have implications for transaction costs. It is also clear, though not explicitly analysed here, that the instrument (or mix of such) may also help reduce compensation payments. With knowledge of forest owner preferences, e.g. as investigated in Lindhjem and Mitani (2012) and Langpap (2004), programs can be targeted to specific groups, types of forest land or geographic areas or similar. Another option, much discussed in the literature and implemented in several countries already, is procurement auctions. Considering such implementation options is the next step from a CBA, to "capture" conservation values at the lowest possible costs. Even if benefits of conservation clearly are higher than costs in many cases, and as shown here, reducing costs may still be important to get public acceptance for implementation.

\footnotetext{
${ }^{33}$ They made, however, such a recommendation for the value of time and the value of statistical life (both elasticity $=1$ )
} 


\section{Acknowledgements}

We would like to acknowledge valuable inputs from the participants at the Biennial workshop in forest economics of the Laboratory of Forest Economics and the European Forest Institut May 30th to June 1st 2012 in Nancy, France. We would also like to thank Asbjørn Tingstad of the Norwegian Directorate for Nature Management, Assistant Professor Pierre-Alexandre Mahieu at the IUT, University of Nantes, France and Petter Gudding from University of Stavanger for valuable inputs. Financial support from the POLICYMIX project (http:nina.policymix.no) funded by the European Commission, Directorate General for Research, within the 7th Framework Programme of RTD, Theme 2 - Biotechnology, Agriculture \& Food ( Grant no. 244065), the Norwegian Research Council AREAL program Grant $173230 / 110$ is greatly appreciated

\section{References}

Amiran, E.Y., Hagen, D.A., 2010. The Scope Trials: Variation in Sensitivity to Scope and WTP with Directionally Bounded Utility Functions. Journal of Environmental Economics and Management 59, 293-301.

Arrow, K.J., Solow, R., Leamer, E., Portney, P., Radner, R., Schuman, H., 1993. Report of the NOAA Panel on Contingent Valuation. Federal Register 58, 4601-4614.

Bateman, I., Cole, M., Cooper, P., Georgiou, S., Hadley, D., Poe, G.L., 2004. On visible choice sets and scope sensitivity. Journal of Environmental Economics and Management 47, 71-93.

Bateman, I.J., Carson, R.T., Day, B., Hanemann, W.M., Hanley, N., Hett, T., Jones-Lee, M., Loomes, G., Mourato, S., Ozdemiroglu, E., Pearce, D.W., Sugden, R., Swanson, T., 2002. Economic Valuation with Stated Preference Techniques: A Manual. Edward Elgar Publishing, Cheltenham, 480pp.

Bateman, I.J., Cooper, P., Georgiou, S., Navrud, S., Poe, G.L., Ready, R.C., Riera, P., Ryan, M., Vossler, C.A., 2005. Economic valuation of policies for managing acidity in remote mountain lakes: Examining validity through scope sensitivity testing. Aquatic Sciences 67, 274-291.

Bergstrom, J.C., Taylor, L.O., 2006. Using meta-analysis for benefits transfer: Theory and practice. Ecological Economics 60, 351-360.

Boadway, R., 2006. Principles of cost-benefit analysis. Public Policy Review 2, 1-44.

Bostedt, G., Mattson, L., 2006. A note on benefits and costs of adjusting forestry to meet recreational demands. Journal of Forest Economics 12, 75-81.

Boyle, K.J., 2003. Contingent valuation in practice, in: Champ, P.A., Boyle, K.J., Brown, T.C. (Eds.), A primer on nonmarket valuation. Kluwer Academic Publishers.

Brouwer, R., Oosterhuis, F.H., Ansink, J.H., Barton, D.N., Lienhoop, N., 2011. POLICYMIX WP 4: Guidelines for estimating costs and benefits of policy instruments for biodiversity conservation.

Cameron, T.A., Huppert, D.D., 1989. Ols Versus Ml Estimation Of Non-Market Resource Values With Payment Card Interval Data. Journal of Environmental Economics and Management 17, 230246.

Chang, W.-Y., Lantz, V.A., Hennigar, C.R., MacLean, D.A., 2012. Benefit-cost analysis of spruce budworm (Christoneura fumiferana Clem.) control: Incorporating market and non-market values. Journal of Environmental Management 93, 104-112.

Chiabai, A., Travisi, C.M., Markandya, A., Ding, H., Nunes, P., 2011. Economic Assessment of Forest Ecosystem Services Losses: Cost of Policy Inaction. Environmental \& Resource Economics 50, 405445.

Dillman, D., 2000. Mail and internet surveys: the tailored design method. John Wiley \& Sons, Inc. 
Framstad, E., Blindheim, T., 2010. Naturfaglig evaluering av Frivillig vern-områder (Natural science assessment of voluntary forest conservation areas), NINA Rapport 534.

Framstad, E., Blindheim, T., Erikstad, L., Thingstad, P.G., Sloreid, S.-E., 2010. Naturfaglig evaluering av norske verneområder (Ecological evaluation of Norwegian protected areas), NINA rapport 535.

Framstad, E., de Wit, H., Mäkipää, R., Larjavaara, M., Vesterdal, L., Karltun, E., 2013. Biodiversity, carbon storage and dynamics or old northern forests, TemaNord 2013:507, Norden.

Framstad, E., Økland, B., Bendiksen, E., Bakkestuen, V., Blom, H., Branderud, T.E., 2002. Evaluering av barskogvernet i Norge (Evaluation of the conservation of coniferous forests in Norway). NINA Fagrapport 54, pp. 1-146.

Gundersen, V., Stange, E., 2011. Opplevelsesverdier i skog - effekter av økologisk og økonomisk informasjon (Recreational values in forests -- effects of ecological and economic information). NINA Rapport 739.

HM Treasury, 2003. The Green Book, http://www.hm-treasury.gov.uk/data_greenbook_index.htm.

Holtsmark, B., 2012. Harvesting in boreal forests and the biofuel carbon debt. Climatic Change 112, 415-428.

Jacobsen, J.B., Lundhede, T., Thorsen, B.J., 2012. Valuation of wildlife populations above survival. Biodiversity Conservation 21, 543-563.

Kniivilä, M., Ovaskainen, V., Saastamoinen, O., 2002. Costs and benefits of forest conservation: regional and local comparisons in Eastern Finland Journal of Forest Economics 8, 131-150.

Kumar, P., 2010. The Economics of Ecosystems and Biodiversity: Ecological and Economic Foundations. Earthscan.

Kålås, J.A., Viken, Å., Henriksen, S., Skjelseth, S., 2010. The 2010 Norwegian Red List for Species Norwegian Biodiversity Information Centre, Norway.

Langpap, C., 2004. Conservation incentives programs for endangered species: An analysis of landowner participation. Land Economics 80, 375-388.

Lehtonen, E., Kuuluvainen, J., Pouta, E., Rekola, M., Li, C.Z., 2003. Non-market benefits of forest conservation in southern Finland. Environmental Science and Policy 6, 195-204.

Lindhjem, H., 2007. 20 Years of stated preference valuation of non-timber benefits from Fennoscandian forests: A meta-analysis. Journal of Forest Economics 12, 251-277.

Lindhjem, H., Magnussen, K., 2012. The value of Norwegian forest ecosystem services (in Norwegian). Report for the public committee on the value of ecosystem services in Norway, NINA Report 894.

Lindhjem, H., Mitani, Y., 2012. Forest owners' willingness to accept compensation for voluntary forest conservation: A contingent valuation approach. Journal of Forest Economics 18, 290-302.

Lindhjem, H., Navrud, S., 2009. Asking for Individual or Household Willingness to Pay for Environmental Goods: Implication for aggregate welfare measures Environmental and Resource Economics 43, 11-29.

Lindhjem, H., Navrud, S., 2011a. Are Internet surveys an alternative to face-to-face interviews in contingent valuation? Ecological Economics 70, 1628-1637.

Lindhjem, H., Navrud, S., 2011b. Using Internet in Stated Preference Surveys: A review and comparison of survey modes. International Review of Environmental and Resource Economics 5, 309351.

List, J.A., Gallet, C.A., 2001. What experimental protocol influence disparities between actual and hypothetical stated values? Environmental and Resource Economics 20, 241-254. 
Loomis, J. (2011) What's to know about hypothetical bias in stated preference valuation studies? Journal of Economics Surveys 25(2): 363-370.

Millennium Ecosystem Assessment, 2005. Synthesis Report. Island Press, Washington DC.

Ministry of Environment (MD), 2013. Press release (in Norwegian) http://www.regjeringen.no/nb/dep/md/pressesenter/pressemeldinger/2013/29-skogomrader-er-vernet-idag.html?id=712642.

Ministry of Finance, 2013. Perspectives ("Perspektivmeldingen" in Norwegian), White Paper to the Norwegian Parliament.

Murphy, J.J., Allen, P.G., Stevens, T.H., Weatherhead, D., 2005. A Meta-Analysis of Hypothetical Bias in Stated Preference Valuation. Environmental and Resource Economics 30, 313-325.

Naidoo, R., Ricketts, T.H., 2006. Mapping the Economic Costs and Benefits of Conservation. PLoS Biology 4.

Norwegian Directorate for Nature Managemnent, 2013. Data on compensations paid under the voluntary forest conservation programme 2005-2013.

Norwegian Ministry of Finance, 2005. Guideline for cost-benefit analysis.

NOU, 2012. Economic Analysis, Recommendations from the Norwegian public committee.

Nybakk, E., Crespell, P., Hansen, E., Lunnan, A., 2009. Antecedents to forest owner innovativeness: An investigation of the non-timber forest products and services sector. Forest Ecology and Management 257, 608-618.

OECD, 2011. OECD Environmental Performance Reviews: Norway 2011.

Raunikar, R., Buongiorno, J., 2006. Willingness to pay for forest amenities: The case of non-industrial owners in the south central United States. Ecological Economics 1, 132-143.

Rollins, K., Lyke, A., 1998. The case for diminishing marginal existence values. J.Environ.Econ.Manage. 36, 324-344.

Sandmo, A., 1998. Redistribution and the marginal cost of public funds. Journal of Public Economics 70, 365-382.

SEPA, 2006. An instrument for assessing the quality of environmental valuation studies. Swedish Environmental Protection Agency.

Skjeggedal, T., Gundersen, V., Harvold, K.A., Vistad, O.I., 2010. Frivillig vern av skog - evaluering av arbeidsform (Voluntary forest conservation - Approach evaluation), NIBR/NINA 2010.

Slaney, G.L., Lantz, V.A., MacLean, D.A., 2010. Assessing costs and benefits of pest management on forested landbases in eastern and western Canada. Journal of Forest Economics 16, 19-34.

TEEB, 2010. The Economics of Ecosystems and Biodiversity: Mainstreaming the Economics of Nature: A synthesis of the approach, conclusions and recommendations of TEEB.

Veisten, K., Hoen, H.F., Strand, J., 2004. Sequencing and the adding-up property in contingent valuation of endangered species: Are contingent non-use values economic values? Environmental and Resource Economics 29, 419-433.

WWF, Friends of the Earth, SABIMA, 2012. Skogkur 2020: A plan for saving Norway's unique forests. 